\title{
Infrastructure Investment and Maintenance Expenditure: Optimal Allocation Rules in a Growing Economy
}

\author{
Pierre-Richard Agénor* \\ Hallsworth Professor of International Macroeconomics \\ and Development Economics \\ University of Manchester, United Kingdom \\ and Centre for Growth and Business Cycle Research
}

First complete draft: August 11, 2005

This version: December 13, 2005

\begin{abstract}
This paper studies the allocation of public expenditure between infrastructure investment and maintenance in an endogenous growth framework. In the basic model maintenance affects both the durability and efficiency of public capital. The balanced growth path is derived and transitional dynamics associated with a revenue-neutral increase in spending on maintenance are analyzed. The growth-maximizing tax rate and share of infrastructure investment are then obtained. The model is then extended to account for the possibility that public spending on maintenance affects also the durability of private capital. Implications for optimal policies are also analyzed.
\end{abstract}

JEL Classification Numbers: O41, H54, E62.

\footnotetext{
*I am grateful to Kyriakos Neanidis and Devrim Yilmaz for helpful comments on a previous draft. The views expressed here, however, are my own.
} 


\section{Contents}

1 Introduction 3

2 Basic Framework $\quad 7$

2.1 Production Structure . . . . . . . . . . . . . 7

2.2 Household-Producer . . . . . . . . . . . . . . . . 8

2.3 Government and Public Capital . . . . . . . . . . . . . 9

3 The Balanced Growth Path 11

4 Expenditure Shift toward Maintenance 13

5 Growth-Maximizing Policies 15

6 Endogenous Private Depreciation $\quad 16$

7 Comparison with other Results $\quad 19$

$\begin{array}{llr}8 & \text { Extensions } & 21\end{array}$

Appendix. Stability Conditions and Uniqueness 24

$\begin{array}{ll}\text { References } & 27\end{array}$

Figure 1: Revenue-Neutral Shift from Infrastructure Investment to Maintenance Expenditure $\quad 29$

Figure 2: Optimal Share of Spending on Maintenance with Endogenous Private Depreciation 


\section{Introduction}

Lack of public spending on maintenance (as opposed to "new" investment) has been a recurrent problem in many developing countries. According to the World Bank (1994, p. 1), technical inefficiencies in roads, railways, power, and water in developing countries caused losses equivalent to a quarter of their annual investment in infrastructure in the early 1990s. Increasing maintenance spending would therefore help to reduce power losses, telephone faults, and so on, and increase the productivity effects of public capital on private production. Thus, to the extent that maintenance expenditure affects the durability, as well as the quality, of public capital, it may stimulate growth. Hulten (1996) argued forcefully indeed for paying more attention to the quality of infrastructure capital in the growth process; and Calderón and Servén (2004) found a link (albeit weak) between indicators of infrastructure quality and the rate of economic growth in a cross-country study.

Analytical studies focusing on the growth effects of maintenance expenditure are scarce and include contributions by Rioja (2003a, 2003b) and Kalaitzidakis and Kalyvitis (2004). ${ }^{1}$ In Rioja (2003a), the quality of infrastructure and the share of public expenditure on maintenance are linearly related, and the depreciation rate of public capital is constant over time. ${ }^{2}$ Thus, increasing maintenance outlays raises the productivity of all inputs used in the production process. In Rioja (2003b), the depreciation rate is

\footnotetext{
${ }^{1}$ Some recent research has also focused on the role of maintenance expenditure in business cycles. Collard and Kollintzas (2002), for instance, developed a model in which they distinguish between labor input devoted directly to production, and labor input devoted to maintaining and improving or scrapping existing capital. Firms first decide the total number of work hours and then how to allocate workers between production and capital maintenance.

${ }^{2} \mathrm{He}$ also assumes, more controversially, that the share of public capital in private production increases with the share of public spending on maintenance.
} 
endogenous and assumed to depend on both the amount of maintenance spending and "usage," as measured by the stock of private physical capital. Maintenance therefore increases the durability of capital; that is, it serves to maintain its effectiveness, rather than raising its efficiency. In both papers reallocating funds from new infrastructure to maintenance can increase the growth rate. Kalaitzidakis and Kalyvitis (2004) developed a model in which the durability of public capital in infrastructure (as measured by its rate of depreciation) is also endogenous and depends on its usage as well as the level of maintenance expenditure. They show that changes in both the level of total expenditure (or, equivalently, the level of taxation) and the share of spending on maintenance affect the steady-state growth rate.

These studies suffer from several limitations. In Rioja (2003b) for instance, maintenance expenditure is financed only through domestic resources (tax revenue), whereas new public investment is financed solely through foreign transfers. As a result, the key issue of the joint determination of the optimal shares of new investment and maintenance spending in total government expenditure, and potential trade-offs between these components, cannot be addressed. Trade-offs between total infrastructure spending and other components of government outlays (such as the provision of education services) cannot be addressed either, despite the obvious importance of the issue if growth depends also on the accumulation of human capital. By contrast, the model developed by Kalaitzidakis and Kalyvitis (2004) does account explicitly for an overall financing constraint on government expenditure, and therefore captures potential trade-offs between components. However, it abstracts entirely from consumption decisions and uses a Tobin's $q$ approach to determine private capital accumulation. As a result, they do not account for the possibility that distortionary taxes may affect the growth rate through 
their impact on consumption and savings decisions. Moreover, they do not derive an explicit expression for the growth-maximizing share of spending on maintenance.

This paper contributes to the existing literature on maintenance expenditure and growth in several ways. I develop an endogenous growth framework in which maintenance expenditure not only increases the durability of public capital, as in Rioja (2003b) and Kalaitzidakis and Kalyvitis (2004), but also raises the efficiency of infrastructure. Given the focus on maintenance, public infrastructure is naturally treated as a stock, as for instance in Arrow and Kurz (1970), Futagami, Morita, and Shibata (1993), Glomm and Ravikumar (1997), Baier and Glomm (2001), Turnovsky (1997, 2000), and Marrero and Novales (2005). ${ }^{3}$ However, there are several differences between these models and the framework developed here. For instance, Glomm and Ravikumar (1997), and Marrero and Novales (2005), assume that private capital depreciates fully each period. Given that they also take returns to scale to be constant in production (as I do here), the economy is always on a balanced growth path. In contrast, transitional dynamics are explicitly studied in the present setting, as in Futagami, Morita, and Shibata (1993). In addition, I also discuss the impact of maintenance spending by the public sector on the private capital stock. The key idea here is that maintaining the quality of (public) roads, for instance, enhances the durability of trucks and other means of transportation used by the private sector to move labor and goods. With a more reliable power grid, electrical equipment may last longer. This extension, as it turns out, has important implications for the determination of optimal policies.

\footnotetext{
${ }^{3}$ Note that in Arrow and Kurz (1970), production is assumed to exhibit diminishing returns to scale with respect to public and private capital, in contrast to the subsequent literature.
} 
The remainder of the paper is organized as follows. Section II presents the basic framework, which assumes that maintenance expenditure affects only the depreciation rate of public capital. Section III determines the balanced growth path, whereas Section IV examines the transitional dynamics and steady-state effects associated with a budget-neutral reallocation of tax revenues from new infrastructure to maintenance. Section V determines the optimal (growth-maximizing) tax rate and share of tax revenues allocated to government spending on infrastructure investment and maintenance. As shown in an early contribution by Barro (1990), if public infrastructure services derive from flow expenditures, the optimal rate of spending (or, equivalently, taxation in his setting) is equal to the elasticity of output with respect to these services. A similar result obtains when the flow of services is produced by the stock of public capital (see Futagami, Morita and Shibata (1993)), or when it is produced by a stock-flow combination (see Tsoukis and Miller (2003)), in the absence of maintenance costs. ${ }^{4}$ The analysis examines whether the presence of maintenance expenditure alters the optimal allocation and discusses why it differs from the Barro rule. The basic framework is then extended in Section VI to consider the case where maintenance expenditure also affects the depreciation rate of private capital. Section VII summarizes the main results of the paper and compares them with those derived in some of the recent contributions cited above. The final section discusses some possible extensions of the analysis.

\footnotetext{
${ }^{4}$ As shown by Turnovsky (1996), however, if private investment is subject to adjustment costs that fall with public services, the positive impact of government spending on growth will be more pronounced than in Barro's rule. The rule will underestimate the optimal tax (and spending) rate.
} 


\section{Basic Framework}

Consider an economy populated by an infinitely-lived representative household, who produces and consumes a single traded good. The good can be used for consumption or investment. The government invests in infrastructure and spends on maintenance. It balances its budget continuously, by levying a flat tax rate on output.

\subsection{Production Structure}

Output, $Y$, is produced with private capital, $K_{P}$, and the effective stock of public infrastructure capital, $e K_{G}$, using a Cobb-Douglas technology: ${ }^{5}$

$$
Y=\left(e K_{G}\right)^{\alpha} K_{P}^{1-\alpha}
$$

where $\alpha \in(0,1), K_{G}$ is the physical stock of public capital, and $e$ its efficiency . Thus, production exhibits constant returns to scale in both factors. ${ }^{6}$ For simplicity, the flow of infrastructure services is assumed to be directly proportional to the effective stock of public capital, which is non-rival and non-excludable. Similarly, $K_{P}$ denotes both the stock of private capital and the flow of services that it provides.

Efficiency is a concave function of the ratio of public spending on maintenance, $M$, to the stock of public capital:

$$
e=\left(\frac{M}{K_{G}}\right)^{\chi}
$$

where $\chi \in(0,1)$.

\footnotetext{
${ }^{5}$ In what follows, time subscripts are omitted for simplicity, and a dot over a variable is used to denote its time derivative.

${ }^{6}$ See Eicher and Turnovsky (1999) for a discussion of the relation between the existence of a balanced growth path and the assumption of constant returns to scale in production in endogenous growth models.
} 
Private capital depreciates at the rate $\delta_{P} \in(0,1)$; the change in $K_{P}$ is thus given by

$$
\dot{K}_{P}=I_{P}-\delta_{P} K_{P}
$$

where $I_{P}$ denotes gross private investment. For the moment, $\delta_{P}$ is taken as given.

\subsection{Household-Producer}

The infinitely-lived representative household-producer maximizes the discounted stream of future utility

$$
\max _{C} U=\int_{0}^{\infty} \ln C \exp (-\rho t) d t
$$

where $C$ is consumption and $\rho>0$ the discount rate. $^{7}$

The household's budget constraint is

$$
C+I_{P}=(1-\tau) Y
$$

where $\tau \in(0,1)$ is the tax rate on output.

The household chooses its consumption path so as to maximize the present value of utility, taking as given the depreciation rate of the private capital stock, the tax rate, and the effective stock of public capital. Using (1), (3), and (5), the current-value Hamiltonian for problem (4) can be written as

$$
H=\ln C+\lambda\left[(1-\tau)\left(e K_{G}\right)^{\alpha} K_{P}^{1-\alpha}-\delta_{P} K_{P}-C\right]
$$

where $\lambda$ is the co-state variable associated with constraint (5). Let $s \equiv$ $(1-\alpha)(1-\tau) \in(0,1)$. From the first-order condition $d H / d C=0$ and

\footnotetext{
${ }^{7}$ The $\log$ specification for instantaneous utility is adopted for simplicity; see Agénor (2005a) for the more general CRRA case. As in that paper, the analysis could also be extended to account for government-provided utility-enhancing services.
} 
the co-state condition $-d H / d K_{P}=\rho \lambda-\dot{\lambda}$, optimality conditions for this problem are given by

$$
\begin{gathered}
1 / C=\lambda, \\
\dot{\lambda}=\lambda\left[\rho+\delta_{P}-s\left(e K_{G} / K_{P}\right)^{\alpha}\right],
\end{gathered}
$$

together with the budget constraint (5) and the transversality condition

$$
\lim _{t \rightarrow \infty} \lambda K_{P} \exp (-\rho t)=0
$$

Equations (6) and (7) can be combined to give

$$
\frac{\dot{C}}{C}=s\left(\frac{e K_{G}}{K_{P}}\right)^{\alpha}-\rho-\delta_{P}
$$

\subsection{Government and Public Capital}

The government invests in infrastructure capital, $I_{G}$, and spends on maintenance. As noted earlier, it collects a proportional tax on output. ${ }^{8}$ Thus, the government budget constraint is given by

$$
I_{G}+M=\tau Y .
$$

Investment in infrastructure and spending on maintenance are both constant fractions of tax revenue, $v_{G}$ and $v_{M}$ :

$$
I_{G}=v_{G} \tau Y, \quad M=v_{M} \tau Y,
$$

with $v_{G}, v_{M} \in(0,1)$. The government budget constraint can thus be rewritten as

$$
v_{G}+v_{M}=1
$$

\footnotetext{
${ }^{8}$ See Hung (2005) for a discussion of the role of seigniorage in models of growth with public investment, and Marrero and Novales (2005) for an examination of lump-sum taxation.
} 
Using (11), the stock of public capital in infrastructure evolves over time according to

$$
\dot{K}_{G}=I_{G}-\delta_{G} K_{G}=v_{G} \tau Y-\delta_{G} K_{G},
$$

where $\delta_{G}$ is the rate of depreciation of public capital in infrastructure, which is taken to depend negatively and linearly on the ratio of maintenance expenditure, $M$, to the public stock of capital, $K_{G}$ :

$$
\delta_{G}=1-\theta_{G}\left(\frac{M}{K_{G}}\right)
$$

where $\theta_{G} \in(0,1){ }^{9}$ Thus, maintenance expenditure enhances the durability of public infrastructure capital. In addition to being convenient analytically, this specification has the property, as noted by Rioja (2003b), that if the government spends nothing on maintenance $(M=0)$, public infrastructure would depreciate entirely $\left(\delta_{G}=1\right)$. However, it differs from the formulation adopted by both Rioja (2003b, p. 2290) and Kalaitzidakis and Kalyvitis (2004, p. 699), which assumes that the depreciation rate is a function of the ratio of maintenance expenditure over output, rather than public capital. The latter is, however, a more natural scaling variable, given that one would expect maintenance needs to depend on the prevailing stock of capital, independently of usage. Regardless of the flow of cars, for instance, roads are likely to deteriorate over time as a result of weather conditions. Similarly, power grids need to be inspected and upgraded on a regular basis (even when usage is low) to prevent losses.

\footnotetext{
${ }^{9}$ This restriction on $\theta_{G}$ is sufficient to ensure that $\delta_{G} \in(0,1)$, as long as $M / K_{G}<1$, as one would expect. Note also that a convex specification, which would require $\delta_{G}^{\prime \prime}>0$, would be much less tractable analytically.
} 


\section{The Balanced Growth Path}

The balanced growth path (BGP) can be determined as follows. First, using (2) and (11), efficiency can be written as

$$
e=\left(\tau v_{M}\right)^{\chi}\left(\frac{Y}{K_{G}}\right)^{\chi}
$$

From (1), $Y / K_{G}=e^{\alpha} k_{G}^{\alpha-1}$, where $k_{G}=K_{G} / K_{P}$. Substituting this result in the above equation and rearranging yields

$$
e=\left(\tau v_{M}\right)^{\chi / \eta} k_{G}^{-(1-\alpha) \chi / \eta}
$$

where $\eta \equiv 1-\alpha \chi>0$.

The household budget constraint (equation (5)) can be rewritten as, using (1) and (3),

$$
\dot{K}_{P}=(1-\tau)\left(\frac{e K_{G}}{K_{P}}\right)^{\alpha} K_{P}-\delta_{P} K_{P}-C
$$

that is,

$$
\frac{\dot{K}_{P}}{K_{P}}=(1-\tau) e^{\alpha} k_{G}^{\alpha}-\delta_{P}-c
$$

where $c=C / K_{P}$. Substituting (15) in this expression yields

$$
\frac{\dot{K}_{P}}{K_{P}}=(1-\tau)\left(\tau v_{M}\right)^{\alpha \chi / \eta} k_{G}^{\alpha(1-\chi) / \eta}-\delta_{P}-c .
$$

Similarly, using (15), equation (9) can be rewritten as

$$
\frac{\dot{C}}{C}=s\left(\tau v_{M}\right)^{\alpha \chi / \eta} k_{G}^{\alpha(1-\chi) / \eta}-\rho-\delta_{P} .
$$

From (11), (13), and (14), and noting that $M / K_{G}=\tau v_{M} Y / K_{G}$,

$$
\frac{\dot{K}_{G}}{K_{G}}=\frac{v_{G} \tau Y}{K_{G}}-\delta_{G}=\tau\left(v_{G}+\theta_{G} v_{M}\right)\left(\frac{Y}{K_{G}}\right)-1,
$$

that is, noting again that $Y / K_{G}=e^{\alpha} k_{G}^{\alpha-1}$ and using (15),

$$
\frac{\dot{K}_{G}}{K_{G}}=\tau\left(v_{G}+\theta_{G} v_{M}\right)\left(\tau v_{M}\right)^{\alpha \chi / \eta} k_{G}^{-(1-\alpha) / \eta}-1 .
$$


Combining equations (16), (17), and (18) yields ${ }^{10}$

$$
\begin{gathered}
\frac{\dot{c}}{c}=-\alpha(1-\tau)\left(\tau v_{M}\right)^{\alpha \chi / \eta} k_{G}^{\alpha(1-\chi) / \eta}+c-\rho, \\
\frac{\dot{k}_{G}}{k_{G}}=\left[\tau\left(\frac{v_{G}+\theta_{G} v_{M}}{k_{G}}\right)-(1-\tau)\right]\left(\tau v_{M}\right)^{\alpha \chi / \eta} k_{G}^{\alpha(1-\chi) / \eta}-1+\delta_{P}+c .
\end{gathered}
$$

These two nonlinear differential equations in $c$ and $k_{G}$, together with the initial condition $k_{G, 0}=K_{G, 0} / K_{P, 0}>0$, and the transversality condition (8), rewritten as

$$
\lim _{t \rightarrow \infty} c^{-1} \exp (-\rho t)=0,
$$

characterize the dynamics of the economy. The BGP is a set of functions $\left\{c, k_{G}\right\}_{t=0}^{\infty}$ such that equations (19) and (20), the budget constraint (12), and the transversality condition (21), are satisfied, and consumption and the stocks of public and private capital, all grow at the same constant rate $\gamma$. This is also the rate of growth of output, given the assumption of constant returns to scale. ${ }^{11}$ Because consumption and the stock of private capital grow at the same constant rate, the ratio $c=C / K_{P}$ is also constant in the steady state; the transversality condition (21) is thus always satisfied along any interior BGP equilibrium.

From (17) and (18), the steady-state growth rate $\gamma$ is given by the equivalent forms

$$
\begin{gathered}
\gamma=s\left(\tau v_{M}\right)^{\alpha \chi / \eta} \tilde{k}_{G}^{\alpha(1-\chi) / \eta}-\rho-\delta_{P}, \\
\gamma=\tau\left(v_{G}+\theta_{G} v_{M}\right)\left(\tau v_{M}\right)^{\alpha \chi / \eta} \tilde{k}_{G}^{-(1-\alpha) / \eta}-1,
\end{gathered}
$$

where $\tilde{k}_{G}$ denotes the stationary value of $k_{G} .{ }^{12}$ As shown in the Appendix, the

\footnotetext{
${ }^{10}$ In deriving $(20)$, note that $-(1-\alpha) / \eta=\alpha(1-\chi) / \eta-1$.

${ }^{11}$ The transversality condition (21) is satisfied along any interior BGP equilibrium because consumption and the stock of private capital grow at the same constant rate, implying that the ratio $c=C / K_{P}$ is also constant in the steady state.

${ }^{12}$ From (16), there is a third equivalent form, $\gamma=(1-\tau)\left(\tau v_{M}\right)^{\alpha \chi / \eta} \tilde{k}_{G}^{\alpha(1-\chi) / \eta}-\delta_{P}-\tilde{c}$. However, given equation (A4) in the Appendix, this expression is identical to (22).
} 
economy is saddlepath stable in the neighborhood of the BGP. Moreover, the BGP is unique under relatively mild conditions. Thus, the model is locally determinate. $^{13}$

The phase diagram in Figure 1 illustrates the adjustment process to the steady state. The phase curve $C C$ represents the combinations of $c$ and $k_{G}$ for which the consumption-private capital stock ratio is constant $(\dot{c}=0)$, whereas the phase curve $K K$ represents the combinations of $c$ and $k_{G}$ for which the public-private capital stock ratio is constant $\left(\dot{k}_{G}=0\right)$. Both curves are strictly increasing and strictly concave, but saddlepath stability requires that the slope of $K K$ be steeper than the slope of $C C$ (see the Appendix). The saddlepath is denoted $S S$ and the initial BGP corresponds to point $A$.

\section{Expenditure Shift toward Maintenance}

Suppose that the government decides to permanently increase the share of spending on maintenance, $v_{M}$, while keeping the tax rate constant $(d \tau=$ 0 ). As a result of the budget constraint (12), the increase in maintenance expenditure must be offset by a reduction in new investment in infrastructure, that is, $d v_{M}=-d v_{G}$.

Figure 1 also illustrates the dynamics associated with this reallocation in spending. As shown in the figure, both $C C$ and $K K$ shift to the left. The spending shift therefore always reduces the steady-state value of the publicprivate capital ratio. However, as shown formally in the Appendix, the net effect on the steady-state value of the consumption-private capital ratio is in

\footnotetext{
${ }^{13}$ To ensure that $\delta_{G}>0$ in the steady state requires that $1-v_{M} \theta_{G} \tilde{k}_{G}^{\alpha-1}>0$. This imposes, in principle, a restriction on the admissible value of $\tilde{k}_{G}$, that is, $\tilde{k}_{G}>\left(v_{M} \theta_{G}\right)^{1 /(1-\alpha)}$. But given that $v_{M}$ and $\theta_{G}$ are both less than unity, this condition is relatively easy to satisfy. For instance, with $v_{M}=0.1, \theta_{G}=0.3$, and $\alpha=0.2$, the steady-state public-private capital ratio must exceed 0.01 .
} 
general ambiguous. The case illustrated in the figure corresponds to the one where curve $K K$ shifts relatively by more than curve $C C$; as a result, in the new long-run equilibrium, the consumption ratio is lower. On impact, the consumption-private capital ratio jumps downward, from point $A$ to point $B$. From then on, the adjustment path proceeds along the new saddlepath $S^{\prime} S^{\prime}$, until the economy reaches the new long-run equilibrium at point $A^{\prime}$.

The net effect of the reallocation of government spending on the growth rate is also ambiguous. As can be inferred from (23) for instance, using (12),

$$
\operatorname{sg}\left\{\left.\frac{d \gamma}{d v_{M}}\right|_{d \tau=0}\right\}=\operatorname{sg}\left\{-\left(1-\theta_{G}\right)+v\left(\frac{\alpha \chi}{\eta v_{M}}-\left.\frac{(1-\alpha)}{\eta \tilde{k}_{G}} \frac{d \tilde{k}_{G}}{d v_{M}}\right|_{d \tau=0}\right)\right\}
$$

where $v \equiv v_{G}+\theta_{G} v_{M}$.

Given that $d \tilde{k}_{G} /\left.d v_{M}\right|_{d \tau=0}<0$ (as noted earlier) and $\theta_{G} \in(0,1)$, the sign of the expression on the right-hand sign is indeed ambiguous in general. The fundamental reason for this ambiguity is of course the fact that both components of spending have a positive effect on the supply side: new investment in infrastructure raises the stock of public capital, whereas higher spending on maintenance increases both the durability, and the efficiency, of the existing stock of capital. Because both types of effect are growth enhancing, a revenue-neutral shift in spending creates a trade-off. In the particular case where $\theta_{G}=1$ (which corresponds to the "maximal" effect of maintenance spending on the depreciation rate) the above equation show that the expenditure shift increases unambiguously the steady-state growth rate. Similarly, the larger the efficiency effect (as measured by $\chi$ ), the more likely it is that the spending shift will increase the growth rate, as well as the steady-state consumption ratio. 


\section{Growth-Maximizing Policies}

Before examining the allocation of spending, I first derive the optimal tax rate, taking the allocation of spending as given (that is, $d v_{M}=d v_{G}=0$ ). From (22) and (23), setting $d \gamma / d \tau=0$ and solving yields the following result:

Proposition 1. The growth-maximizing tax rate is given by $\tau^{*}=\alpha$, as predicted by the Barro rule.

Thus, despite the fact that maintenance spending has a positive effect on the efficiency of public infrastructure - and thus the productivity of private capital - as well as the durability of public capital, the optimal policy calls for a tax rate that reflects only the elasticity of the effective public capital stock in production, in line with the result established by Barro (1990). ${ }^{14}$

Consider now the case where the government sets optimally the share of revenue allocated to maintenance, for a given tax rate (that is, $d \tau=0$ ). Thus, from the budget constraint (12), $d v_{G}=-d v_{M}$. Using this restriction, and setting $d \gamma / d v_{M}=0$ in (22) and (23) yields the following proposition:

Proposition 2. The growth-maximizing share of spending on maintenance is given by

$$
v_{M}^{*}=\frac{\chi}{1-\theta_{G}}
$$

This solution is admissible as long as $\chi+\theta_{G}<1$. Assuming that this condition holds, Proposition 2 shows that the optimal share of spending on maintenance is positively related (as could be expected) to $\chi$, the elasticity of the efficiency function with respect to maintenance. At the same time, a higher response of the depreciation rate to spending on maintenance (that is,

\footnotetext{
${ }^{14}$ In a model without maintenance, Futagami, Morita, and Shibata (1993) proved that the Barro rule holds if it is the stock of capital in infrastructure, rather than the flow of infrastructure services, that affects production.
} 
an increase in $\theta_{G}$ ) tends to raise the share of spending on that category. Put differently, the more "effective" public spending on maintenance is in terms of raising the durability of public capital, the higher should be the share of tax revenues allocated to it.

\section{Endogenous Private Depreciation}

The foregoing analysis took the rate of depreciation of private capital, $\delta_{P}$, as given. I now consider the case where $\delta_{P}$ is endogenous and linearly related to the ratio of government spending on maintenance, $M$, to the private capital stock:

$$
\delta_{P}=1-\theta_{P}\left(\frac{M}{K_{P}}\right)
$$

where $\theta_{P} \in(0,1) \cdot{ }^{15}$ As noted in the introduction, the view taken here is that maintenance expenditure on public capital enhances also the durability of private capital. With better roads, trucks used to move goods and workers across different geographic regions may last longer. If maintenance spending increases the reliability of publicly-provided sources of energy (such as electricity), machines and other equipment such as computers used by private sector firms may break down less often; and so on. "Usage" (of public infrastructure) is therefore properly measured by the size of the private capital stock.

The household continues to take the depreciation rate as given while solving its maximization problem; the optimal solution path for consumption is thus the same as before. Using (11), (25), and (15), it is straightforward

\footnotetext{
${ }^{15}$ This restriction on $\theta_{P}$ is, again, sufficient to ensure that $\delta_{P} \in(0,1)$, as long as $M / K_{P}<1$.
} 
to show that equations (16) and (17) now become

$$
\begin{gathered}
\frac{\dot{C}}{C}=\left(s+\theta_{P} \tau v_{M}\right)\left(\tau v_{M}\right)^{\alpha \chi / \eta} k_{G}^{\alpha(1-\chi) / \eta}-\rho-1, \\
\frac{\dot{K}_{P}}{K_{P}}=\left(1-\tau+\theta_{P} \tau v_{M}\right)\left(\tau v_{M}\right)^{\alpha \chi / \eta} k_{G}^{\alpha(1-\chi) / \eta}-c-1,
\end{gathered}
$$

whereas equation (18) remains the same. Combining equations (18), (26), and (27) yields a dynamic system in $c$ and $k_{G}$, whose stability conditions are essentially the same as before. I therefore omit mathematical details and focus directly on growth-maximizing policies.

The steady-state growth rate $\gamma$ is given by (23), as before, and the equivalent form (26) with $\dot{C} / C=\gamma$ and $k_{G}=\tilde{k}_{G}$. Setting $d \gamma / d \tau=0$ in these equations with $d v_{M}=d v_{G}=0$ yields, after some manipulations, the following result:

Proposition 3. With maintenance spending also affecting the depreciation rate of private capital, the growth-maximizing tax rate is given by

$$
\tau^{*}=\left\{1-\frac{\alpha \theta_{P}}{1-\alpha} v_{M}\right\}^{-1} \alpha>\alpha .
$$

This solution is admissible if the initial spending share on maintenance is not too large. Assuming that this is the case, formula (28) implies that the optimal tax rate is positively related to $\theta_{P}$, the marginal effect of an increase in maintenance spending on the depreciation rate of private capital. This is in contrast with the previous result regarding $\theta_{G}$, which was shown to have no effect on $\tau^{*}$. Similarly, the higher the initial share of spending on maintenance, the higher the optimal tax rate.

Solving as before for the growth-maximizing share of spending on maintenance, for a given tax rate and imposing $d v_{G}=-d v_{M}$, leads to the following 
optimality condition:

$$
v_{M}^{*}\left(\alpha s+\theta_{P} \tau v_{M}^{*}\right)-\frac{\theta_{P} \tau v_{M}^{*}[1-\alpha(1-\chi)]}{1-\theta_{G}}-\frac{\alpha s \chi}{1-\theta_{G}}=0,
$$

which corresponds to (24) with $\theta_{P}=0$. In general, however, with $\theta_{P}>0$, this condition yields a quadratic form in $v_{M}^{*}$ and an explicit solution is quite murky. In particular, it cannot be proved that the resulting optimal value is higher or lower than the value shown in (24) for an arbitrarily set value of $\theta_{P}$. Nevertheless, a graphical technique can be used to determine the impact of $\theta_{P}$ on $v_{M}^{*}$ - the issue of interest here.

The terms in equation (29) can be written as

$$
G_{1}\left(v_{M}^{*}\right)=v_{M}^{*}\left(\alpha s+\theta_{P} \tau v_{M}^{*}\right), \quad G_{2}\left(v_{M}^{*}\right)=\frac{\alpha s \chi}{1-\theta_{G}}+\frac{\theta_{P} \tau v_{M}^{*}}{1-\theta_{G}} \Omega,
$$

where $\Omega \equiv 1-\alpha(1-\chi)$. Thus, $G_{1}\left(v_{M}^{*}\right)$ is a convex function of $v_{M}^{*}$, whereas $G_{2}\left(v_{M}^{*}\right)$ is a linear function of $v_{M}^{*}$. Both curves are shown in Figure 2. Optimality requires $G_{1}\left(v_{M}^{*}\right)=G_{2}\left(v_{M}^{*}\right)$, which is obtained at point $A$.

A rise in $\theta_{P}$ rotates curve $G_{1}\left(v_{M}^{*}\right)$ inward, whereas curve $G_{2}\left(v_{M}^{*}\right)$ shifts upward. Whether the new equilibrium point, $A^{\prime}$, corresponds to a higher value of $v_{M}^{*}$ depends on the relative shift in the two curves. Suppose that $\theta_{G}=0$ for simplicity; it can then be shown that this relative shift depends on whether the initial value of $v_{M}^{*}$ is greater or lower than $\Omega$. The higher the value of $\chi$, the more likely it is that $\Omega>v_{M}^{*}$, and the larger the shift in $G_{2}\left(v_{M}^{*}\right)$ relative to $G_{1}\left(v_{M}^{*}\right)$. Now, if $\theta_{G}$ is not zero, it is easy to verify that the higher $\theta_{G}$ is, the more likely it is indeed that $\Omega>v_{M}^{*}$, for a given value of $\chi$. The case $\Omega>\left(1-\theta_{G}\right) v_{M}^{*}$ is the one represented in Figure 2; assuming that the solution is admissible, it implies therefore the following proposition.

Proposition 4. Suppose that the effect of maintenance expenditure on the efficiency and/or durability of the public capital stock is sufficiently high. 
Then the higher the marginal effect of maintenance spending on the depreciation rate of private capital, the higher the growth-maximizing share of spending on maintenance.

Intuitively, maintenance spending on public capital must be sufficiently "productive" for an increase in the marginal effect of these outlays on the rate of depreciation of private capital to lead to higher public expenditure on maintenance.

\section{Comparison with other Results}

The foregoing discussion has established two main sets of results. First, if maintenance spending affects only the depreciation rate of public infrastructure capital, the Barro rule (which relates the tax rate solely to the elasticity of output with respect to public capital, $\alpha$ ) is optimal, whereas the growthmaximizing share of spending on maintenance depends only on the efficiency parameter $\chi$ and the marginal effect on the depreciation rate. An important feature of this solution is also that the marginal effect of maintenance on the depreciation rate matters only if maintenance affects at the same time the efficiency of public capital; if $\chi=0$, then $v_{M}^{*}=0$, regardless of the value of $\theta_{G}$. Moreover, the optimal share of spending on infrastructure $\left(v_{G}^{*}=1-v_{M}^{*}\right)$ does not depend on $\alpha$, in contrast to the result established by Rioja (2003b, p. 2292). Second, if maintenance spending enhances the durability of both private and public capital, the Barro rule is sub-optimal, and the growthmaximizing share of spending on maintenance depends in a complex way on the structural parameters characterizing the production side, as well as the tax rate. Nevertheless, if maintenance spending has a sufficiently strong positive effect on efficiency and the depreciation rate of public capital, an 
increase in the marginal effect of maintenance on private capital, $\theta_{P}$, will reduce the optimal share of spending on infrastructure.

It is worth comparing these results with those derived by Kalaitzidakis and Kalyvitis (2004). In their model, the depreciation rate of public capital is also endogenously related to maintenance expenditure, but efficiency effects are not accounted for and the depreciation rate of private capital is exogenous. They found that the optimal tax rate is not independent of the uses to which proceeds from taxation are put: the share of maintenance expenditure in output affects positively the optimal tax rate. Moreover, in their model, the Barro rule is sub-optimal. The reason, they argue, is that an additional unit of new investment generates a need for additional spending on maintenance, in order to sustain the extra usage of the public capital stock and maintain its durability.

The results established in the present paper are quite different from those derived by Kalaitzidakis and Kalyvitis (2004). First, and more importantly, the optimal tax rate does not depend on the share of spending on maintenance, if such spending affects only the durability of public capital. Put differently, whether the services of an additional "effective" unit of public capital are brought about by an increase in new investment (that is, a rise in the stock of capital itself), or by an increase in spending on maintenance (which improves either the durability or the efficiency of the existing stock), does not matter from the point of view of setting the growth-maximizing tax rate. The only parameter that matters therefore is the elasticity of output with respect to the effective stock of public capital, $\alpha$. Second, it is important to account for the fact that the rate of depreciation of private physical capital may depend also on public spending on maintenance. It is only when doing so that the Barro rule can be shown to be sub-optimal, and that the growth- 
maximizing tax rate depends on the share of spending on maintenance (an effect that can be rationalized along the lines suggested by Kalaitzidakis and Kalyvitis (2004)). Moreover, the share of resources that should be allocated to maintenance expenditure may depend positively not only on its marginal effect on public capital, but also on it ability to enhance the durability of the private capital stock. Neglecting this effect may result in a sub-optimal allocation of resources toward new investment in infrastructure.

\section{Extensions}

This paper studied the optimal allocation of government spending between investment in infrastructure and maintenance expenditure, in an endogenous growth framework. This issue is important not only analytically but also empirically: inadequate funding for infrastructure maintenance has been a chronic problem in many countries in the developing world, resulting in rapid decay of public capital, such as roads and power grids. At the same time, many of these countries are now engaged in the design of infrastructure-led growth strategies. Understanding, from a growth perspective, the trade-offs involved in allocating resources between investment in infrastructure and maintenance of public capital may thus provide useful guidelines for the formulation of medium-term public expenditure programs in that context.

The main results of the paper were summarized in the previous section and contrasted with those derived in some recent contributions. In lieu of concluding remarks, it is perhaps worth examining in what directions the analysis can be extended. First, the analysis could be modified to assume that maintenance affects not only the durability of public capital but also its quality, maintenance spending by the private sector could also be explicitly 
introduced in the model and determined as part of the optimization problem solved by the representative household-producer. By accounting for the fact that private spending on maintenance affects also the quality of the private capital stock, it could be shown that optimal private spending on maintenance may depend on the quality-adjusted public capital stock. With better roads, for instance, the private sector would need to spend less on maintaining trucks used for transporting goods. Thus, an additional channel would be introduced for a positive growth effect of an increase in public spending on maintenance: by reducing the need for private sector spending on maintenance, more resources can be allocated to private capital accumulation.

Second, more general specifications could be introduced to relate the depreciation rate to maintenance expenditure, and to account for the fact that congestion (excessive usage of public goods) may affect not only the marginal productivity of public capital in private production (as recognized in several recent studies, such as Turnovsky (1997)) but also the durability of public (and private) capital. For instance, the depreciation rate could be assumed to be a convex function of the ratio of public capital to output, in addition to the share of spending on maintenance. A related issue would then be to explore how the model can be used to determine optimal user charges to cover maintenance costs (taking into account congestion effects), simultaneously with the determination of the growth-maximizing allocation of public spending and within the context of the overall government budget constraint. Determining sustainable mechanisms to finance outlays associated with infrastructure maintenance remains indeed a major challenge for governments in the developing world. As far as I know, this perspective on user charges and congestion effects has not yet been explored in any depth.

Finally, in the present model, it was assumed that both maintenance 
expenditure and investment are financed domestically. An alternative is to follow Rioja (2003b) and Chatterjee and Turnovsky (2005) and assume that domestic tax revenues are used to finance maintenance expenditure (as well as other productivity-enhancing services, such as education and health), whereas "new" investment is financed in part (rather than exclusively, as assumed by Rioja (2003b)) by international donors. This approach would be particularly relevant to discuss growth and poverty reduction strategies in low-income developing countries in the current international context, where (as noted earlier) large increases in public investment in infrastructure, financed by foreign aid, have been called for to spur growth. The "optimal" level of aid could therefore be derived as part of the government's maximization problem. 


\section{Appendix \\ Stability Conditions and Uniqueness}

The dynamic system consists of equations (19) and (20), which are repeated here for convenience:

$$
\begin{gathered}
\frac{\dot{c}}{c}=-\alpha(1-\tau)\left(\tau v_{M}\right)^{\alpha \chi / \eta} k_{G}^{\alpha(1-\chi) / \eta}+c-\rho, \\
\frac{\dot{k}_{G}}{k_{G}}=\left[\frac{\tau v}{k_{G}}-(1-\tau)\right]\left(\tau v_{M}\right)^{\alpha \chi / \eta} k_{G}^{\alpha(1-\chi) / \eta}-1+\delta_{P}+c,
\end{gathered}
$$

where $v \equiv v_{G}+\theta_{G} v_{M}=1-\left(1-\theta_{G}\right) v_{M}<1$.

To investigate the dynamics in the vicinity of the steady state, this system can be linearized to give

$$
\left[\begin{array}{c}
\dot{c} \\
\dot{k}_{G}
\end{array}\right]=\left[\begin{array}{ll}
a_{11} & a_{12} \\
a_{21} & a_{22}
\end{array}\right]\left[\begin{array}{c}
c-\tilde{c} \\
k_{G}-\tilde{k}_{G}
\end{array}\right],
$$

with the $a_{i j}$ given by $a_{11}=\tilde{c}, a_{21}=\tilde{k}_{G}$, and

$$
\begin{gathered}
a_{12}=-\frac{\alpha^{2}(1-\chi)}{\eta} \tilde{c}(1-\tau)\left(\tau v_{M}\right)^{\alpha \chi / \eta} \tilde{k}_{G}^{\alpha(1-\chi) / \eta-1}<0, \\
a_{22}=-\left[\frac{(1-\alpha) v}{\eta \tilde{k}_{G}}+(1-\tau) \frac{\alpha(1-\chi)}{\eta}\right]\left(\tau v_{M}\right)^{\alpha \chi / \eta} \tilde{k}_{G}^{(1-\chi) / \eta}<0,
\end{gathered}
$$

where $\tilde{x}$ denotes the stationary value of $x . c$ is a jump variable, whereas $k_{G}$ is predetermined. Saddlepath stability requires one unstable (positive) root. To ensure that this condition holds, the determinant of the Jacobian matrix of partial derivatives of the dynamic system (A3) must be negative, that is, $a_{11} a_{22}-a_{12} a_{21}<0$, or equivalently, $-a_{12} / a_{11}<-a_{22} / a_{21}$. It can be verified that this condition always holds. Curve $K K$ in Figure 1 is therefore steeper than $C C$. The slope of the saddlepath $S S$, which is given by $\kappa \equiv-a_{12} /(\tilde{c}-\nu)$, where $\nu$ is the negative root of the system, is positive.

From (A1), setting $\dot{c}=0$ yields

$$
\tilde{c}=\rho+\alpha(1-\tau)\left(\tau v_{M}\right)^{\alpha \chi / \eta} \tilde{k}_{G}^{\alpha(1-\chi) / \eta} .
$$

Substituting (A4) in (A2) with $\dot{k}_{G}=0$ yields the implicit function

$$
F\left(\tilde{k}_{G}\right)=\left\{\frac{\tau v}{\tilde{k}_{G}}-(1-\alpha)(1-\tau)\right\}\left(\tau v_{M}\right)^{\alpha \chi / \eta} \tilde{k}_{G}^{\alpha(1-\chi) / \eta}-1+\delta_{P}+\rho=0 .
$$


To show that the BGP is unique, note first that from (A5),

$$
F_{\tilde{k}_{G}}=-\left\{\frac{(1-\alpha) \tau v}{\eta \tilde{k}_{G}}+\frac{\alpha(1-\alpha)(1-\tau)(1-\chi)}{\eta}\right\}\left(\tau v_{M}\right)^{\alpha \chi / \eta} \tilde{k}_{G}^{(1-\chi) / \eta-1}<0 .
$$

Thus, $F\left(\tilde{k}_{G}\right)$ cannot cross the horizontal axis from below. Now, suppose that $\rho+\delta_{P}>1$; then $F(0)>0$. Given that $F\left(\tilde{k}_{G}\right)$ is a continuous, monotonically decreasing function of $\tilde{k}_{G}$, there is a unique positive value of $\tilde{k}_{G}$ that satisfies $F\left(\tilde{k}_{G}\right)=0$. From (A4), there is also a unique positive value of $\tilde{c}$.

Equations (A4) and (A5) can be used to determine the steady-state effects of a revenue-neutral increase in the share of spending on maintenance expenditure on $\tilde{c}$ and $\tilde{k}_{G}$, as discussed in the text. Specifically, using the implicit function theorem, it can be established that a rise in $v_{M}$, compensated by a reduction in $v_{G}$, has a negative effect on $\tilde{k}_{G}$ and, from $(\mathrm{A} 4)$, on $\tilde{c}$ as well. Indeed, $d \tilde{k}_{G} / d v_{M}=-F_{v_{M}} / F_{\tilde{k}_{G}}$; given that, as shown above, $F_{\tilde{k}_{G}}<0$, $\operatorname{sg}\left(d \tilde{k}_{G} / d v_{M}\right)=\operatorname{sg}\left(F_{v_{M}}\right)$. In turn, $F_{v_{M}}$ is equal to, in the "neutral" case where $d v_{M}+d v_{G}=d \tau=0$,

$$
\left.F_{v_{M}}\right|_{d \tau=0}=\left[\frac{\alpha \chi}{\eta v_{M}}\left\{\frac{\tau v}{\tilde{k}_{G}}-(1-\alpha)(1-\tau)\right\}-\frac{\tau\left(1-\theta_{G}\right)}{\tilde{k}_{G}}\right]\left(\tau v_{M}\right)^{\alpha \chi / \eta} \tilde{k}_{G}^{\alpha(1-\chi) / \eta},
$$

that is, using (A5) to substitute for the first term,

$$
\left.F_{v_{M}}\right|_{d \tau=0}=\frac{\alpha \chi\left(1-\delta_{P}-\rho\right)}{\eta v_{M}}-\frac{\tau\left(1-\theta_{G}\right)}{\tilde{k}_{G}}\left(\tau v_{M}\right)^{\alpha \chi / \eta} \tilde{k}_{G}^{\alpha(1-\chi) / \eta} .
$$

As noted earlier, to ensure that $F(0)>0$ requires imposing $\rho+\delta_{P}>1$; thus, the first term in this expression is negative. The second is also negative, given that $\theta_{G}<1$. Thus, $\left.F_{v_{M}}\right|_{d \tau=0}<0$; a budget-neutral increase in $v_{M}$ unambiguously lowers the steady-state value of $\tilde{k}_{G}$.

From the steady-state condition (A4),

$$
\operatorname{sg}\left\{\left.\frac{d \tilde{c}}{d v_{M}}\right|_{d \tau=0}\right\}=\operatorname{sg}\left\{\chi v_{M}^{\alpha \chi / \eta-1}+\left.(1-\chi) \tilde{k}_{G}^{\alpha(1-\chi) / \eta-1} \frac{d \tilde{k}_{G}}{d v_{M}}\right|_{d \tau=0}\right\},
$$

which is in general ambiguous. If $\chi$ is sufficiently small, the expression on the left-hand side will be unambiguously negative, and $d \tilde{c} /\left.d v_{M}\right|_{d \tau=0}<0$, as illustrated in Figure 1. 
To show that in that case $c$ jumps downward on impact, note that the equation of the saddlepath is

$$
c=\tilde{c}+\kappa\left(k_{G}-\tilde{k}_{G}\right),
$$

where $\kappa$ is defined above. From (A6), the impact effect of a budget-neutral rise in $v_{M}$ on the consumption-private capital ratio is, given that $k_{G}$ cannot change instantaneously,

$$
\left.\frac{d c_{0}}{d v_{M}}\right|_{d \tau=0}=\left.\frac{d \tilde{c}}{d v_{M}}\right|_{d \tau=0}-\left.\kappa \frac{d \tilde{k}_{G}}{d v_{M}}\right|_{d \tau=0},
$$

which can be shown to be negative. 


\section{References}

Agénor, Pierre-Richard, "Infrastructure, Public Education and Growth with Congestion Costs," Working Paper No. 47, Centre for Growth and Business Cycle Research, University of Manchester (January 2005a). Forthcoming, European Journal of Political Economy.

_ - "Fiscal Policy and Growth with Public Infrastructure," Working Paper No. 59, Centre for Growth and Business Cycle Research, University of Manchester (October 2005b).

—_ "Schooling and Public Capital in a Model of Endogenous Growth," Working Paper No. 61, Centre for Growth and Business Cycle Research, University of Manchester (October 2005c).

Arrow, Kenneth J., and Mordecai Kurz, Public Investment, the Rate of Return, and Optimal Fiscal Policy, Johns Hopkins University Press (Baltimore, Md: 1970).

Barro, Robert J., "Government Spending in a Simple Model of Endogenous Growth," Journal of Political Economy, 98 (October 1990), s103-s25.

Calderón, César, and Luis Servén, "The Effects of Infrastructure Development on Growth and Income Distribution," Policy Research Working Paper No. No. 3400, World Bank (September 2004).

Chatterjee, Santanu, and Stephen J. Turnovsky, "Financing Public Investment through Foreign Aid: Consequences for Economic Growth and Welfare," Review of International Economics, 13 (March 2005), 20-44.

Collard, Fabrice, and Tryphon Kollintzas, "Maintenance, Utilization, and Depreciation along the Business Cycle," Discussion Paper No. 2477, Centre for Economic Policy Research (June 2002).

Eicher, Theo, and Stephen J. Turnovsky, "Non-Scale Models of Endogenous Growth," Economic Journal, 109 (July 1999), 394-415.

—_, "Scale, Congestion, and Growth," Economica, 67 (August 2000), 325-46.

Futagami, Koichi, Yuichi Morita, and Akihisa Shibata, "Dynamic Analysis of an Endogenous Growth Model with Public Capital," in Endogenous Growth, ed. by Torben M. Andersen and Karl O. Moene, Basil Blackwell (Oxford: 1993).

Glomm, Gerhard, and B. Ravikumar, "Productive Govenment Expenditures and Long-Run Growth," Journal of Economic Dynamics and Control, 21 (January 1997), 183-204.

_ - "Flat-Rate Taxes, Government Spending on Education and Growth," Review of Economic Dynamics, 1 (January 1998), 306-25. 
Hulten, Charles R., "Infrastructure Capital and Economic Growth: How Well you Use it may be more Important than how much you Have," Working Paper No. 5847, National Bureau of Economic Research (December 1996).

Hung, Fu-Sheng, "Optimal Composition of Government Public Capital Financing," Journal of Macroeconomics, 27 (December 2005), 704-23.

Kalaitzidakis, Pantelis, and Sarantis Kalyvitis, "On the Macroeconomic Implications of Maintenance in Public Capital," Journal of Public Economics, 88 (March 2004), 695-712.

Marrero, Gustavo A., and Alfonso Novales, "Growth and Welfare: Distorting versus Non-Distorting Taxes," Journal of Macroeconomics, 27 (September 2005), 403-33.

Rioja, Felix K., "Productiveness and Welfare Implications of Public Infrastructure: A Dynamic Two-Sector General Equilibrium Analysis," Journal of Development Economics, 58 (April 1999), 387-404.

—_, "The Penalties of Inefficient Infrastructure," Review of Development Economics, 7 (March 2003a), 127-37.

_ _ "Filling Potholes: Macroeconomic Effects of Maintenance versus new Investment in Public Infrastructure," Journal of Public Economics, 87 (September 2003b), 2281-304.

Tsoukis, Chris, and Nigel J. Miller, "Public Services and Endogenous Growth," Journal of Policy Modeling, 25 (April 2003), 297-307.

Turnovsky, Stephen J., "Fiscal Policy in a Growing Economy with Public Capital," Macroeconomic Dynamics, 1 (September 1997), 615-39.

_ - "Fiscal Policy, Elastic Labor Supply, and Endogenous Growth," Journal of Monetary Economics, 45 (February 2000), 185-210.

World Bank, Investing in Infrastructure, World Development Report 1994, Oxford University Press (New York: 1994). 
Figure 1

Revenue-Neutral Shift from Infrastructure Investment to Maintenance Expenditure

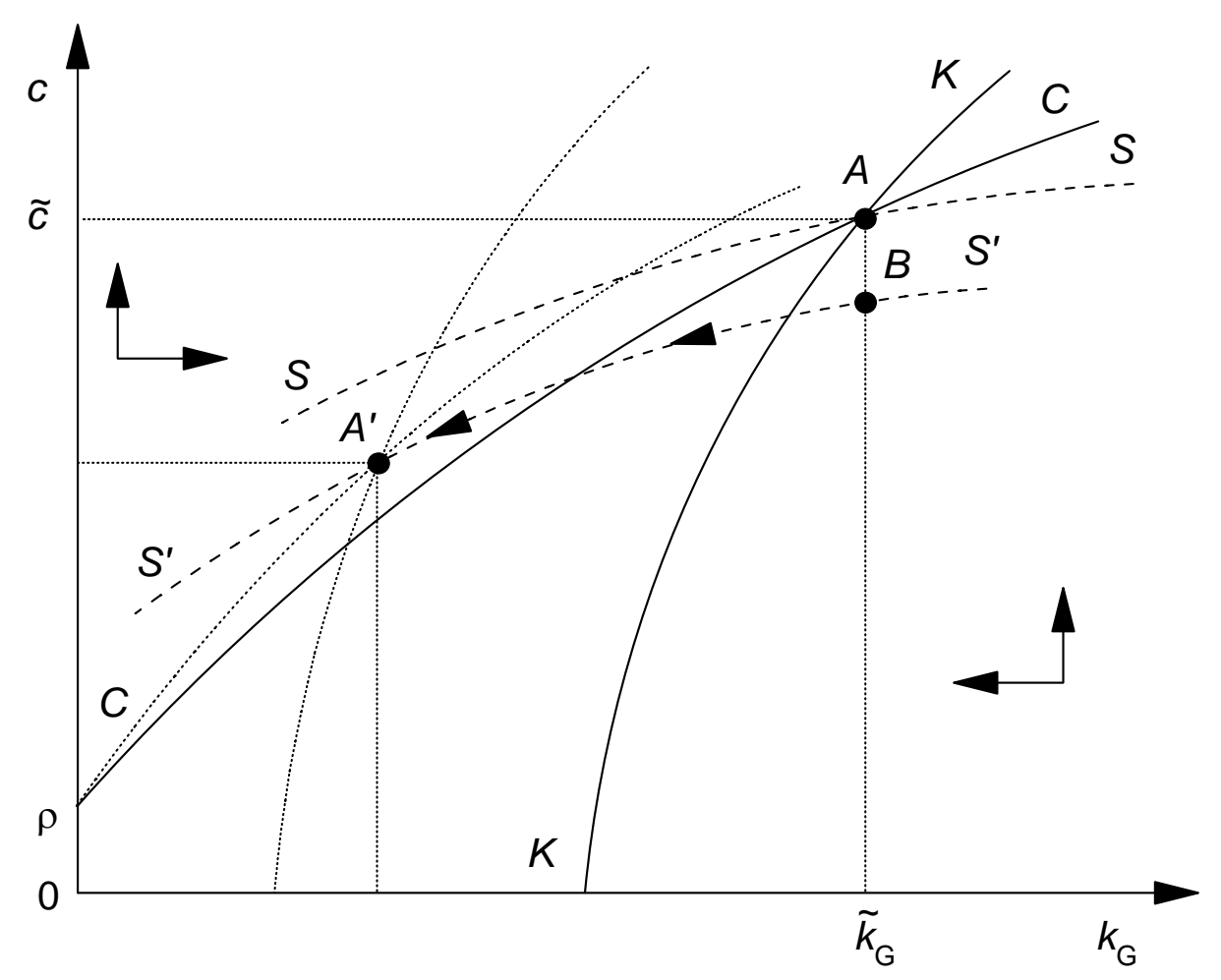


Figure 2

Optimal Share of Spending on Maintenance with Endogenous Private Depreciation

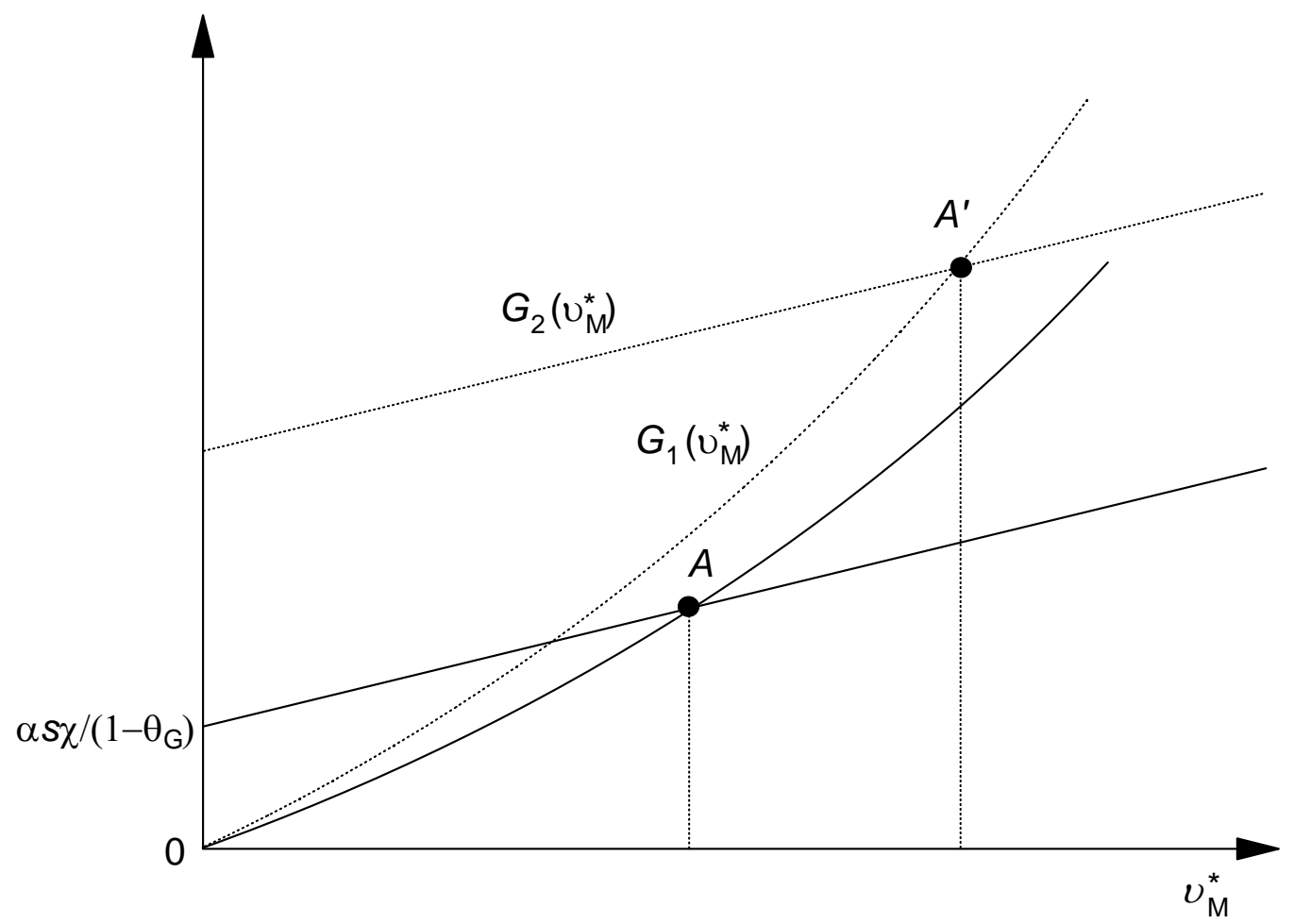

